\title{
A systematic review of endovascular treatment for chronic total occlusion of the internal carotid artery
}

\author{
Piotr Myrcha ${ }^{1} \wedge$, Peter Gloviczki ${ }^{\wedge} \wedge$ \\ ${ }^{1}$ Department of General and Vascular Surgery, Faculty of Medicine, Medical University of Warsaw, Warsaw, Poland; ${ }^{2}$ Division of Vascular and \\ Endovascular Surgery, Mayo Clinic, Rochester, Minnesota, USA \\ Contributions: (I) Conception and design: Both authors; (II)Administrative support: Both authors; (III) Provision of study materials or patients: Both \\ authors; (IV) Collection and assembly of data: Both authors; (V) Data analysis and interpretation: Both authors; (VI) Manuscript writing: Both \\ authors; (VII) Final approval of manuscript: Both authors. \\ Correspondence to: Piotr Myrcha, MD. Department of General and Vascular Surgery, Faculty of Medicine, Medical University of Warsaw, ul. \\ Kondratowicza 8, 03-242 Warsaw, Poland. Email: piotrmyr@poczta.fm.
}

\begin{abstract}
The management of patients with symptomatic chronic total occlusion (CTO) of the internal carotid artery (ICA) is controversial. The aim of this systematic review was to investigate patient selection, technical success, early and late outcome of endovascular treatment for CTO of the ICA. PubMed/Medline and EMBASE databases were searched until January 2, 2020 for studies on endovascular treatment for CTO of the ICA. A descriptive analysis of demographic, clinical and anatomic data, endovascular technique, perioperative and late outcomes was performed. A total of 1,222 articles were screened, 8 retrospective or prospective cohort studies were reviewed; 276 patients, $18.9 \%$ females, mean age: 64.3 years, underwent attempt at endovascular treatment of 278 lesions. Two hundred and thirteen patients $(77.2 \%)$ had neurological symptoms; the others had evidence of ipsilateral cerebral hypoperfusion. Two hundred and thirty-eight lesions $(91.2 \%)$ were treated $>30$ days after diagnosis of occlusion. Technical success was $66.9 \%$. Perioperative mortality was $1.64 \%$ (4/243), early stroke rate was 3.3\%. Follow-up averaged 23.4 months (range, $0.25-84$ months), late mortality was $1.89 \%$ (5/265), stroke rate was $3.4 \%(9 / 265)$. Stroke rate was similar after successful stenting $(3.57 \%, 4 / 112)$ vs. failed stenting $(3.61 \%, 2 / 61 ; \mathrm{P}=1.00)$, stroke/death rates were also similar after successful stenting $(5.36 \%, 6 / 112)$ than after failed stenting $(3.28 \%, 2 / 61 ; \mathrm{P}=0.71)$. Endovascular treatment of CTO of the ICA in eight cohort studies was safe and feasible with a technical success of $67 \%$ and a low rate of early and late neurological complications. Pooled data in this review failed to confirm the benefit of successful stenting on stroke and mortality, but some of the included studies suggest benefit and some also supported improvement in neurocognitive function after successful stenting. Prospective randomized trials to investigate the benefit of endovascular treatment in addition to best medical therapy for symptomatic CTO of the ICA are urgently needed.
\end{abstract}

Keywords: Carotid artery stenting; chronic total occlusion; endovascular treatment/therapy; internal carotid artery

Submitted Oct 18, 2020. Accepted for publication Mar 09, 2021.

doi: $10.21037 / \mathrm{atm}-20-6980$

View this article at: http://dx.doi.org/10.21037/atm-20-6980

^ ORCID: Piotr Myrcha, 0000-0002-6683-429X; Peter Gloviczki, 0000-0002-9352-8044. 


\section{Introduction}

The management of patients with chronic total occlusion (CTO) of the internal carotid artery (ICA) continues to be controversial. Those with CTO and symptoms of transient or permanent neurological deficits are at increased risk to develop recurrent stroke either due to embolism from the ipsilateral ICA stump, from stenosis of the ipsilateral external carotid artery (ECA), from an ipsilateral common carotid artery (CCA) plaque, from the contralateral stenosed ICA or due to cerebral hypoperfusion caused by low flow. In spite of progress in medical therapy and in management of risk factors of atherosclerosis, the annual risk of a recurrent stroke has not decreased over four decades (1). An Olmsted county population based epidemiologic study found the risk of cerebral infarction was $8 \%$ at 30 days, $10 \%$ at 1 year, and $14 \%$ at 5 years after ICA occlusion (2). In a meta-analysis of 44 studies published between 1961 and 1999, the annual rate of recurrent stroke was 5.5\% (95\% CI: 5.1-6.0, range, $0-26.9 \%)$, the annual rate of vascular death was $4.0 \%(95 \%$ CI: 3.5-4.5; range, 0-13.8\%, 23 studies) while the rate of stroke or vascular death was $8.9 \%$ /year (95\% CI: 7.7-10.1; range, $0-19.5 \% ; 22$ studies) (1). Patients on anticoagulation had lower stroke rate (rate ratio 0.86; 95\% CI: 0.79-0.93) than those who were taking aspirin only.

Open surgical interventions for decreasing the risk of embolism and improving cerebral perfusion have been limited to endarterectomy of the ipsilateral stenosed ECA or endarterectomy of the contralateral stenosed ICA (3). Cerebral perfusion can occasionally be helped by reconstructing a narrowed vertebral artery or the first segment of an occluded subclavian artery (4). In the randomized Carotid Occlusion Surgery Study, extracranialintracranial (EC-IC) bypass surgery added to best medical therapy failed to reduce subsequent ipsilateral ischemic stroke in patients with recently symptomatic CTO of the ICA and hemodynamic cerebral ischemia (5).

Endovascular recanalization of chronically occluded ICA was first reported by Terada et al. in 2005 (6). Since then, multiple case reports $(7-18)$ retrospective and prospective cohort studies (19-28) have been published, most claiming benefit in patients who underwent successful endovascular or hybrid treatment, but no randomized controlled studies are available and society guidelines so far have failed to recommend endovascular therapy for symptomatic CTO of the ICA $(29,30)$. The aim of this systematic review was to investigate patient selection, technical success, periprocedural complications, early and late outcome of endovascular treatment for symptomatic CTO of the ICA.

We present the following article in accordance with the PRISMA reporting checklist (available at http://dx.doi. org/10.21037/atm-20-6980).

\section{Methods}

A systematic review was conducted according to the Preferred Reporting Items for Systematic Reviews and Meta-Analysis (PRISMA) statement (31). PubMed/ Medline and EMBASE was searched until January 2, 2020 for clinical research studies including case reports, case series, retrospective observational studies, prospective cohort studies or randomized controlled trials to identify endovascular procedures (EPs) performed in patients with CTO of the ICA. Two independent reviewers assessed each study. A descriptive analysis of demographic and epidemiological data, preoperative neurological status, time interval from occlusion to intervention, technical success, perioperative and late outcomes, including stroke, transient ischemic attack (TIA), amaurosis fugax (AF), bleeding and other major complications and mortality was performed. Fisher's exact test was used to calculate differences in stroke and stroke/death rates between the successfully stented and failed groups.

\section{Results}

\section{Study selection}

Using the term "chronic carotid occlusion" we identified 1,222 articles (Figure 1). After introducing filters that eliminated non-English, non-human, acute carotid occlusion, non-surgical, non-endovascular, non-hybrid reports, we were left with 56 publications: 27 articles on EP (13 cohort studies, 14 case/case series reports), 23 on open surgery (20 cohort studies, 3 case reports) and 6 articles on hybrid techniques (3 cohort studies, 3 case reports). Two of the cohort studies on hybrid technique had more than 10 cases treated with EPs; those were added to the $13 \mathrm{EP}$ cohort studies $(27,28)$. After excluding all EP case reports with less than 10 cases, all open surgical papers and four of the 6 hybrid treatment articles, we finished up with 15 EP cohort studies. Several articles were published from the same institution in Taiwan, we selected one of their papers with the largest number $(n=138)$ of patients for our study (24). Data from two additional papers from this institution were also used to identify perioperative 


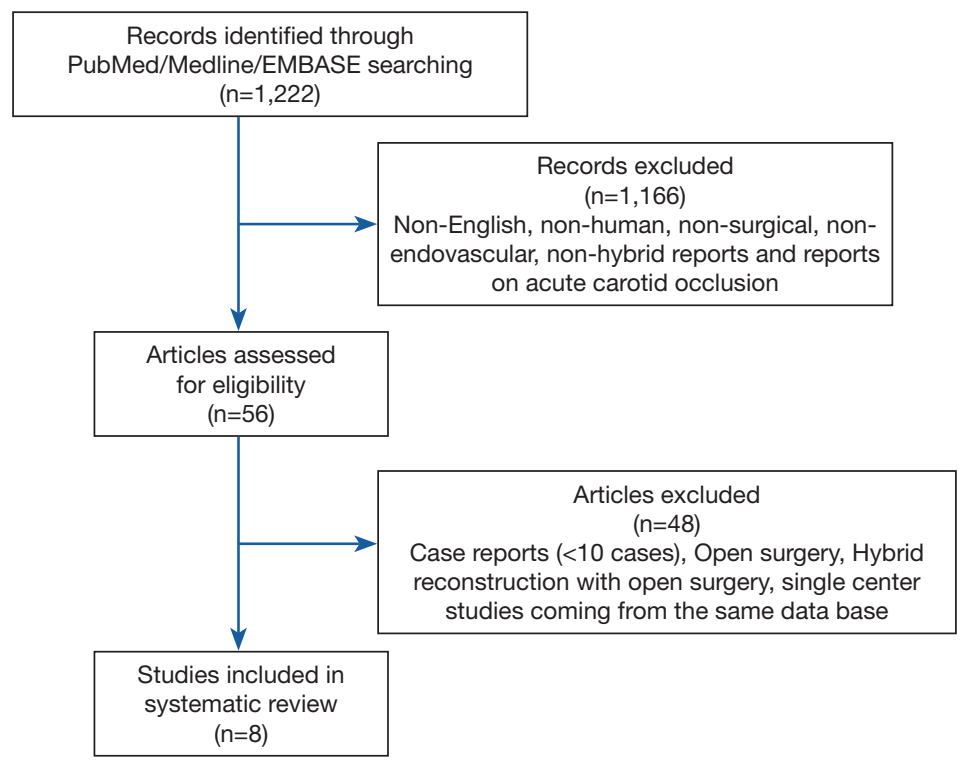

Figure 1 PRISMA flow diagram with the number of studies screened, excluded and included into the systematic review.

complications, specifically carotid-cavernous arteriovenous fistula (CCAVF) and long-term outcome $(25,26)$. The final systematic review included 276 patients from 8 observational studies. Four studies were from China $(21,22,27,28)$ two from Japan $(19,20)$ one from Taiwan $(24)$ and another from the United States (23).

\section{Patient selection}

All patients underwent an attempt at endovascular recanalization for CTO of the ICA. Symptomatic CTO of the ICA was considered if neurological or ophthalmologic symptoms appeared after the diagnosis of occlusion. Neurological symptoms included focal, ipsilateral symptoms (TIA, AF or stroke) or generalized symptoms due to cerebral hypoperfusion. The Taiwan group also included patients without neurological symptoms, if there was objective evidence of decreased ipsilateral cerebral perfusion based on brain computed tomography (CT) perfusion with acetazolamide $(24,32)$. The diagnosis of chronic CTO was made if the time interval between the diagnosis of occlusion and the intervention was $>30$ days (33). Some studies included patients with subacute (8-30 days) or acute total occlusion (1-7 days).

\section{Demographic data}

Two hundred seventy-eight lesions were treated in 276 patients, with a mean age of 64.3 years, ranging from 40 to 86 years. Gender was reported on 264 patients, $49(18.7 \%)$ were females (Table 1$)$.

\section{Pre-procedure neurologic status}

All except one study included symptomatic patients only. Sixty of 138 patients (43.5\%) in the study of Chen et al. (24) had no neurological symptoms but had objective evidence of ipsilateral cerebra hypoperfusion confirmed by CT perfusion with acetazolamide. Overall, 213 of 276 patients $(77.2 \%)$ had neurological symptoms of TIA, $\mathrm{AF}$ or stroke. Specific neurological symptoms were defined in 7 publications and included TIA. or AF in $38.4 \%$ (53/138) and stroke in $67.4 \%(93 / 138)$. Symptoms of cerebral hypoperfusions were defined for 4 patients in one study (23) but not defined for those 60 patients in the Taiwan study, who did not have NASCET (33) neurological symptoms.

\section{Timing of carotid stenting after occlusion}

Pooled analysis revealed 238 lesions (91.2\%) were CTOs, 


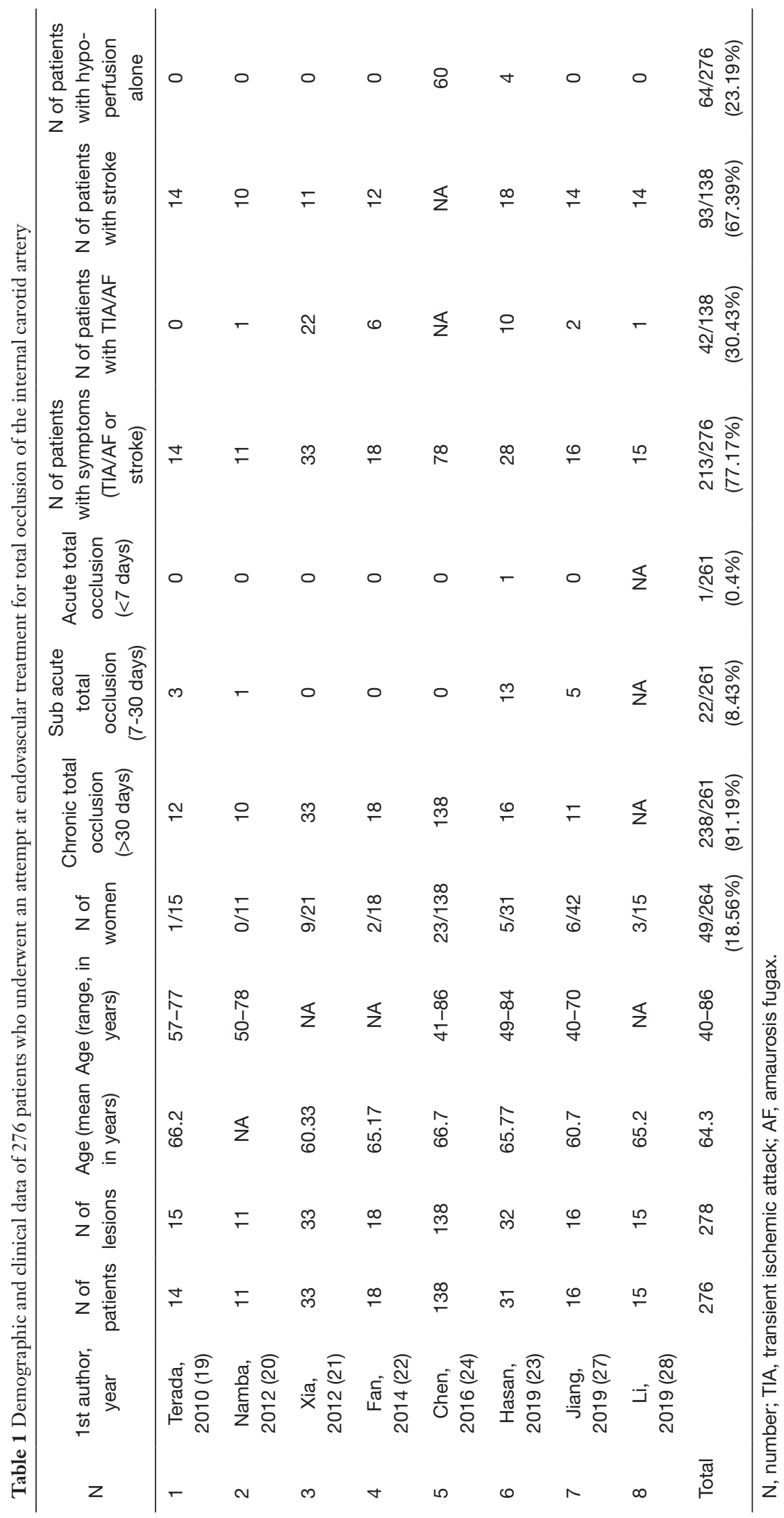



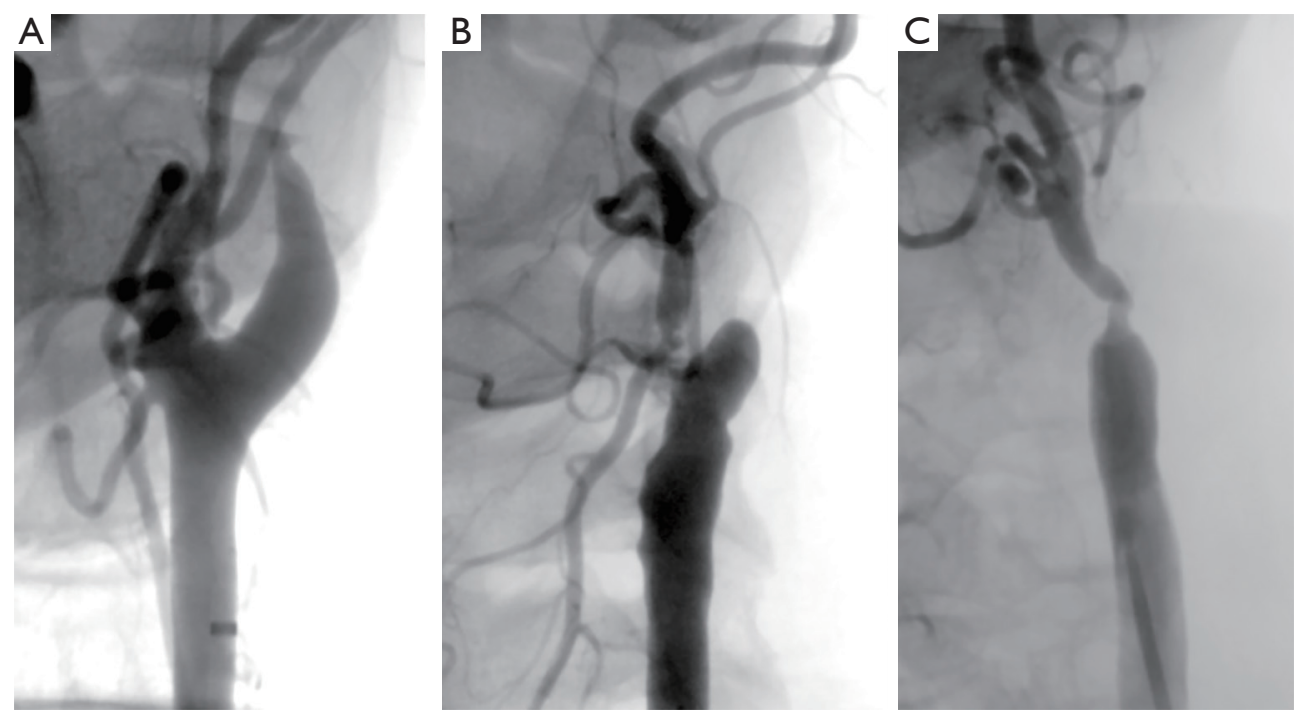

Figure 2 Internal carotid artery chronic total occlusion-types of stumps. (A) Taper stump; (B) non-taper stump (blunt); (C) non stump.

Table 2 Anatomic data of the internal carotid artery (ICA) occlusion

\begin{tabular}{|c|c|c|c|c|c|c|c|}
\hline$N$ & 1st author, year & $\begin{array}{c}\text { Occlusion } \\
\text { cervical ICA }\end{array}$ & $\begin{array}{l}\text { Occlusion petrous } \\
\text { or cavernous ICA }\end{array}$ & $\begin{array}{c}\text { Occlusion } \\
\text { length }>5 \mathrm{~cm}\end{array}$ & $\begin{array}{l}\text { Taper } \\
\text { stump }\end{array}$ & $\begin{array}{l}\text { Non-taper } \\
\text { stump }\end{array}$ & Non-stump \\
\hline 1 & Terada, 2010 (19) & 10 & 4/15 (26.67\%) & NA & NA & NA & NA \\
\hline 3 & Xia, 2012 (21) & 33 & NA & NA & NA & NA & NA \\
\hline 4 & Fan, 2014 (22) & NA & NA & NA & NA & NA & NA \\
\hline 6 & Hasan, 2019 (23) & 32 & $24 / 32(75 \%)$ & NA & $8 / 31(25.8 \%)$ & $8 / 31$ (25.8\%) & $16 / 31(51.61 \%)$ \\
\hline 7 & Jiang, 2019 (27) & 16 & NA & 2/16 (12.5\%) & NA & NA & NA \\
\hline 8 & Li, 2019 (28) & 15 & NA & $13 / 15(86.6 \%)$ & $0 / 15$ & $9 / 15(60 \%)$ & $6 / 15(40 \%)$ \\
\hline
\end{tabular}

NA, data not available.

with intervention performed $>30$ days after diagnosis of occlusion. There were, however, 22 lesions (8.4\%) that were subacute total occlusion (7-30 days), and 1 patient $(0.4 \%)$ had acute total occlusion within 7 days. Time interval from diagnosis to procedure was not known for 17 lesions.

\section{Internal carotid artery stump}

The most common classification distinguishes three groups based on the anatomy of the ICA stump: taper stump, nontaper (blunt) stump and non stump (Figure 2) (28). Five of the eight studies reported on stump anatomy, three presented it in detail, most (61.4\%) had tapered stump (Table 2). Only one group favored carotid arteries with blunt stump and penetrated the stump with the guidewire at the anterior side (20).

\section{Internal carotid artery occlusion length and location}

Due to different classifications used in the studies, it was not possible to accurately compare the carotid artery anatomy from different series. A simplified classification 
distinguished between short $(<50 \mathrm{~mm})$ and long $(>50 \mathrm{~mm})$ occlusions. Most occlusions (87\%) in the pooled review were cervical.

\section{Antiplatelet treatment and anticoagulation}

For antiplatelet pre-treatment seven studies reported on using dual antiplatelet therapy, acetylsalicylic acid (75-300 mg) combined either with clopidogrel (75-300 mg), cilostazol $(200 \mathrm{mg})$ or ticlopidine $(200 \mathrm{mg})$ daily, from 1 to 7 days before surgery. Heparin was given intraoperatively to maintain activated clotting time within 200 to 300 seconds. In selected cases the glycoprotein IIb/ IIIa receptor antagonist Abciximab or the thrombin inhibitor Argatroban were administered intravenously to prevent thrombotic complications. To prevent vasospasm, two groups reported to use intraoperative intravenous infusion of nimodipine (Bayer Pharma AG, Leverkusen, Germany) (21,27).

\section{Technique of endovascular procedure}

All EPs were performed through percutaneous transfemoral access of the common femoral artery. To cross the CTO, most groups used various types of $0.014-0.018$ " guidewires with soft to intermediate stiffness, three groups started with 0.035 " guidewire, sometimes using the technique "back end first" (23). In most papers, attempts were made to cross the occlusion with multiple guidewires of varying diameter and rigidity, using microcatheters, balloons or sheaths as needed.

\section{Stents}

In most cases, the location and number of implanted stents depended on the length of occlusion and the state of the artery after predilation. Stenting the cervical segment of ICA was performed with dedicated self-expanding stents. Three groups used single cervical stenting $(21,27,28)$. three used multiple cervical stenting to reconstruct the extracranial ICA $(19,22,24)$. Namba et al. used multiple cervical and intracranial stents for reconstruction of the occluded, stenosed and dissected ICA segments (20). For intracranial stenting most authors used balloon expandable coronary stents. In rare cases only balloon angioplasty was performed (28).

\section{Cerebral protection}

A cerebral protection device was used during EP in all except one study (22). Four groups used only distal protection device $(21,23,24,27)$ one only proximal protection device (PPD) (19) and two groups used both techniques interchangeably $(20,28)$. The Parodi antiembolic system (ArteriA, San Francisco, CA, USA) was the most commonly used PPD (34).

\section{Technical success}

Technical success averaged $66.9 \%$, ranged from $53 \%$ to $93 \%$ and depended on the length $(<5$ or $>5 \mathrm{~cm})$ and location (cervical, intracranial) of the occlusion and on any intraoperative complications (dissection, inability to return to the true lumen or creation of an intramural or extramural hematoma or cavernous arteriovenous fistulas) (Table 3).

\section{Perioperative outcomes}

\section{Mortality}

Perioperative mortality in the pooled data was $1.64 \%$ (4/243). It was not reported in one study (Table 3).

\section{Neurological complications}

All except one study (21) reported on early total neurological complications that occurred in $3.7 \%(9 / 243)$, with a stroke rate of $3.3 \%$ and a rate of TIA of $0.4 \%$. One study reported a stroke rate of $26.7 \%$ (4/15), with 1 mortality $(6.7 \%)(28)$.

\section{Carotid-cavernous arterio-venous fistula}

Two series discussed the development of carotid-cavernous arteriovenous fistula (CCAVF) $(23,24)$. The Taiwan experience with 11 cases of iatrogenic CCAVF was reported in a separate publication by Yeh et al. (26) CCAVF was detected during wire crossing attempt or after balloon angioplasty. In 4 out of 11 patients balloon angioplasty effectively treated CCF. None of the patients received urgent stenting. In the cases reported by Hasan et al. (23) 
Table 3 Embolic protection, technical success and perioperative outcome

\begin{tabular}{|c|c|c|c|c|c|c|c|}
\hline $\mathrm{N}$ & $\begin{array}{l}\text { 1st author, } \\
\text { year }\end{array}$ & $\begin{array}{l}\text { Embolic } \\
\text { protection }\end{array}$ & $\begin{array}{l}\text { Technical } \\
\text { success }\end{array}$ & $\begin{array}{l}\text { Perioperative } \\
\text { stroke }\end{array}$ & $\begin{array}{l}\text { Perioperative } \\
\text { TIAVAF }\end{array}$ & $\begin{array}{l}\text { Perioperative } \\
\text { mortality }\end{array}$ & Perioperative complications \\
\hline 1 & Terada, 2010 & Proximal & $14 / 15$ & 0 & 0 & 0 & $\begin{array}{l}1 \text { embolism, with transient increase in } \\
\text { neurologic deficit, } 4 \text { dissections, } \\
1 \text { subadventitial hematoma }\end{array}$ \\
\hline 2 & Namba, 2012 & $\begin{array}{l}\text { Proximal } \\
\text { and distal }\end{array}$ & $8 / 11$ & 0 & 0 & 0 & $\begin{array}{l}1-9 \text { high intensity ischemic lesions on } \\
\text { DWI, 3-14 mm, in } 7 / 11 \text { patients (64\%) }\end{array}$ \\
\hline 4 & Fan, 2014 & None & $16 / 18$ & 0 & 0 & 0 & 0 \\
\hline 5 & Chen, 2016 & Distal & $85 / 138$ & $2 / 138$ (1.4\%) & 0 & $2 / 138(1.4 \%)$ & $\begin{array}{l}\text { CHS } 2 \text { pt, } 2 \text { with intracerebral bleeding, } \\
\text { overall complications } 6 / 138 \text { ( } 4.3 \%) \text {. } \\
11 \text { patients had CCF (Yeh et al. 2018.) }\end{array}$ \\
\hline Total & & & $186 / 278$ (66. 9\%) & $8 / 243(3.29 \%)$ & $1 / 243(0.41 \%)$ & 4/243 (1.64\%) & $36 / 243(15.64 \%)$ \\
\hline
\end{tabular}

DWI, diffusion weighted imaging; CCF, carotid-cavernous fistula.

most CCF resolved after 10-15 minutes of observation.

\section{Intracranial hemorrhage}

Intracranial bleeding was observed in $6 \%$ in one of the studies, all were limited to minor/silent hemorrhagic infarcts. The Taiwan group, however, reported a $2 \%$ incidence of intracranial hemorrhage, that caused the death of 2 patients (25).

\section{Late outcomes}

Mortality beyond 30 days was reported in 5 of 265 patients $(1.89 \%)$.

\section{Stroke}

During the pooled follow-up period that averaged 23.4 months (range, $0.25-84$ months) stroke occurred in $3.4 \%(9 / 265)$ and 5 patients $(1.89 \%)$ had TIA or AF (Table 4). Stroke rate was similar after successful stenting $(3.57 \%, 4 / 112) v s$. failed stenting $(3.61 \%, 2 / 61 ; \mathrm{P}=1.0)$ and stroke/death rates were also similar after successful stenting $(5.36 \%, 6 / 112$; ) than after failed stenting. (3.28\%, 2/61; $\mathrm{P}=0.71)$. Cerebral and gastrointestinal bleeding occurred after 30 days in one patient each.

\section{Reocclusion}

Stent thrombosis beyond 30 days was reported in 3 studies only and ranged from 0 to $15 \%(19,25)$.

\section{Discussion}

This systematic review of the literature analyzed data of 276 patients published in eight cohort studies to collect information on the technical success rate, on safety and feasibility of an endovascular procedure to recanalize CTO of the ICA and to investigate the risk of recurrent stroke, major complications and procedure related death in patients who undergo successful stenting or who fail an attempt at endovascular recanalization. Patients who have transient hemispheric or ocular ischemia, ipsilateral hemispheric stroke or ipsilateral cerebral hypoperfusion in spite of best medical treatment were candidates for endovascular treatment for CTO. In the analyzed cohort 278 lesions of 276 patients $(77.2 \%)$ were symptomatic before the procedure, but all neurologically asymptomatic patients had evidence of cerebral hypoperfusion confirmed with CT perfusion of acetazolamide. associated with CTO (24). Two hundred and thirty-eight patients (91.2\%) had symptoms $>30$ days before intervention. Dual antiplatelet treatment 
Table 4 Late outcome after endovascular treatment for total occlusion of the internal carotid artery

\begin{tabular}{|c|c|c|c|c|c|c|c|}
\hline $\mathrm{N}$ & 1st author, year & $\begin{array}{l}\text { Follow-up mean } \\
\text { (months) }\end{array}$ & $\begin{array}{l}\text { Follow up (FU) } \\
\text { range, (months) }\end{array}$ & Stroke & $\mathrm{TIA} \mathrm{AF}{ }^{*}$ & Mortality & Complications \\
\hline 1 & Terada, 2010 & 26.1 & $2-56$ & 0 & 0 & 0 & 0 \\
\hline 2 & Namba, 2012 & 0.25 & No late FU & NA & NA & NA & NA \\
\hline 3 & Xia, 2012 & 29.4 & $3-60$ & 2/21 (9.52\%) & 2/21 (9.52\%) & $1 / 21(4.76 \%)$ & 1 cerebral hemorrhage \\
\hline 6 & Hasan, 2019 & 15.1 & $0.25-54$ & 2/32 (6.25\%) & 2/32 (6.25\%) & 0 & 0 \\
\hline 7 & Jiang, 2019 & 10.5 & $3-15$ & 1 & 1 & 0 & $1 \mathrm{Gl}$ **bleeding \\
\hline 8 & Li, 2019 & 11.67 & NA & $2(14.3 \%)$ & 0 & $1(6.7 \%)$ & 0 \\
\hline
\end{tabular}

*, transient ischemic attack/amaurosis fugax; ${ }^{* *}$, gastrointestinal.

before and after CAS and full intravenous heparinization during the procedure was applied universally by all teams. This review found that in experienced hands EP can be performed with a technical success of $66.9 \%$, with a perioperative mortality of $1.64 \%$ and an early stroke rate of $3.29 \%$. The early and mid-term results were acceptable. It became apparent, however that several factors play a key role in the success of these complex procedures.

Selecting the appropriate patient with CTO with suitable anatomy for stenting is particularly important, since in this review one of three attempts at revascularization failed. Preoperative imaging should differentiate CTO from nearocclusion and pseudo-occlusion. Near-occlusion with or without full collapse may contain loose intraluminal thrombus with the possibility of embolism during an attempt at endovascular treatment (35).

In the case of pseudo-occlusion of the cervical ICA, the cervical segment contains loose secondary thrombus and the occlusive lesion is located in the intracranial part of ICA. Magnetic resonance (MR), computed tomography (CT), digital subtraction angiography and Duplex Ultrasound (DUS) are useful in diagnostics. The anatomy of the stump was imperative for most investigators and a tapered stump, that was present in $61 \%$ of the cases in our review was the one most investigators favored for success. Chen et al. reported a lower success rate in non-tapered $v s$. tapered stumps (OR: 0.33; 95\% CI: 0.13 to 0.82) (24).

The length of the occlusion was a major determinant of success in most studies. Hasan et al. (23) had 100\% success in patients with $<5 \mathrm{~cm}$ occlusion of the cervical ICA, compared to $50 \%$ success in longer lesions, especially when it extended into the intracerebral ICA. The Taiwan group (36) described similar results ( $89 \%$ success rate of short vs. $52 \%$ success rate of long occlusions. Interestingly, Chen et al. (24) recorded a lower success rate of recanalization of occlusions in asymptomatic patients (OR: 0.45 ; $95 \%$ CI: 0.22 to 0.96 ).

Effective interventional techniques to protect the brain from embolism during the procedure, to cross the occlusion and reenter into the true lumen with a combination of fine, soft and stiff guidewires, with the help of microcatheters, balloons, sheaths, without perforating the wall of the artery are also key to success. All except one group used cerebral protection and Parodi's original or modified technique of flow reversal has been used with increasing frequency (37).

Intracranial hemorrhage (IH) can occur after successful recanalization due to hyperperfusion syndrome or it can also occur from perforation of the artery with the guidewire during the procedure Such complication is fortunately rare but can be severe requiring craniotomy and it could cause the death of the patient. To minimize the risk of hyperperfusion syndrome, it is important to closely monitor blood pressure after revascularization and keep it strictly $<120 \mathrm{mmHg}$ (38). Carotid-cavernous fistula appears to be a self-limiting complication and it is noteworthy that none of the patients with CCAVF developed intracranial hemorrhage, stroke, or death.

Data from multiple studies indicate that patients who undergo successful stenting for CTO of the ICA have a lower rate of recurrent neurological deficit than those who fail an attempt at endovascular treatment. Recurrent 
cerebrovascular events during a mean follow-up of $11.22 \pm 3.28$ months occurred in $9.4 \%(3 / 32)$ in the study of Li et al. (28), who reported on both endovascular and hybrid revascularization, but all events occurred in patients who failed CAS, increasing the event rate to $33.3 \%(3 / 9)$ in the failed group and 0 in the successfully recanalized patients. Kao et al. (25) followed 118 patients up to 7 years after CAS for TCO of the ICA and found cumulative neurological events or death in 17 patients after successful stenting and in 23 after failed stenting (HR 0.51, 95\% CI: 0.27-0.97; $\mathrm{P}=0.04$ ). Pooled analysis of our data, however, failed to confirm a significant decrease in stroke or stroke and death following successful stenting $v$ s. failed attempt at stenting. This can be due to short follow-up or a Type II error because of the relatively small number of patients in each study group.

In a non-randomized controlled study Xia et al. (21) compared outcome in 21 patients, who were successfully treated with carotid artery stenting (CAS) for CTO with that of 41 patients who underwent best medical therapy. The modified Rankin Scale score was used to measure functional outcome and it was significantly lower in the CAS group at 2 years $(\mathrm{P}<0.01)$. The combined cerebrovascular events plus mortality were also significantly lower $(\mathrm{P}<0.05)$ in the CAS group vs. controls, but there was no difference in cerebrovascular events $(28.6 \% \mathrm{vs}$. $46.3 \%, \mathrm{P}=0.088$ ) or in mortality (4.8\% vs. 9.8\%, $\mathrm{P}=0.247$ ). In another non-randomized prospective study Fan et al. compared outcomes of 18 patients treated with EP to those of 22 patients on best medical therapy (22). Patients who underwent successful stenting had a significantly better improvement in cognitive function at 6 months using Montreal Cognitive Assessment (MoCA) test than those who received best medical therapy $(\mathrm{P}=0.001)$. During a mean follow-up of 10.2 months, however, no significant difference was noted in stroke or death rate between the groups. Improvement in neurocognitive function as well as attention and psychomotor processing speed after successful carotid artery stenting in patients with chronic internal carotid artery occlusion was confirmed by others as well (39).

Pires Coelho et al. (40) performed a systematic review and meta-analysis of 1,000 emergency carotid stenting procedures in patients with acute ischemic stroke due to tandem occlusions. Emergency ICA stenting increased time to revascularization and increased the risk of complications with no demonstrated clinical benefit. Revascularization in acute and chronic ICA occlusions is performed for different purposes and using different methods. It is not appropriate to compare these procedures.

Our systematic review has several limitations. First, the number of patients and studies was small, most observational studies were retrospective reviews with lack of a control group, and the studies had significant heterogeneity because of differences in design. Second, diversity in reporting standards, data collection, patient enrollment, endovascular technique, operator experience and the short followup for most studies were clear limitations that have to be acknowledged. Third, discrimination of data between the asymptomatic and symptomatic patients and between those with subacute and chronic total occlusions were not feasible. Fourth, we have not analyzed data of 14 papers that reported case series under ten patients or single case reports, since a favorable outcome in these cases due to publication bias was clearly expected.

In conclusions, transfemoral stenting for CTO of the ICA is feasible in carefully selected patients with CTO of the ICA with a technical success rate of $67 \%$ when performed by experienced teams using cerebral protection combined with adjuvant anticoagulation and antiplatelet treatment. In some of the studies successful stenting for CTO of the ICA decreased neurologic complications $v s$. those who had failed stenting but analysis of pooled data in this review failed to confirm a significant difference between the two groups. Small non-randomized studies also suggest improved neurocognitive function after successful stenting but showed no difference in stroke or mortality when compared to best medical therapy. Prospective randomized trials, comparing endovascular treatment in addition to best medical therapy for symptomatic CTO of the ICA with best medical therapy alone are urgently needed.

\section{Acknowledgments}

Funding: None.

\section{Footnote}

Provenance and Peer Review: This article was commissioned by the Guest Editor (Kosmas I. Paraskevas) for the series "Carotid Artery Stenosis and Stroke-Prevention and Treatment Part II" published in Annals of Translational Medicine. The article has undergone external peer review.

Reporting Checklist: The authors have completed the PRISMA reporting checklist. Available at http://dx.doi. org/10.21037/atm-20-6980 
Conflicts of Interest: Both authors have completed the ICMJE uniform disclosure form (available at http://dx.doi. org/10.21037/atm-20-6980). The series "Carotid Artery Stenosis and Stroke-Prevention and Treatment Part II" was commissioned by the editorial office without any funding or sponsorship. The authors have no other conflicts of interest to declare.

Ethical Statement: The authors are accountable for all aspects of the work in ensuring that questions related to the accuracy or integrity of any part of the work are appropriately investigated and resolved.

Open Access Statement: This is an Open Access article distributed in accordance with the Creative Commons Attribution-NonCommercial-NoDerivs 4.0 International License (CC BY-NC-ND 4.0), which permits the noncommercial replication and distribution of the article with the strict proviso that no changes or edits are made and the original work is properly cited (including links to both the formal publication through the relevant DOI and the license). See: https://creativecommons.org/licenses/by-nc-nd/4.0/.

\section{References}

1. Klijn CJ, Kappelle LJ, Algra A, et al. Outcome in patients with symptomatic occlusion of the internal carotid artery or intracranial arterial lesions: a meta-analysis of the role of baseline characteristics and type of antithrombotic treatment. Cerebrovasc Dis 2001;12:228-34.

2. Flaherty ML, Flemming KD, McClelland R, et al. Population-based study of symptomatic internal carotid artery occlusion: incidence and long-term follow-up. Stroke 2004;35:e349-52.

3. Fokkema M, Reichmann BL, den Hartog AG, et al. Selective external endarterectomy in patients with ipsilateral symptomatic internal carotid artery occlusion. J Vasc Surg 2013;58:145-51.e1.

4. Persoon S, van Berckel BN, Bremmer JP, et al. Intervention versus standard medical treatment in patients with symptomatic occlusion of the internal carotid artery: a randomised oxygen-15 PET study. EJNMMI Res 2013;3:79.

5. Powers WJ, Clarke WR, Grubb RL, Jr., et al. Extracranialintracranial bypass surgery for stroke prevention in hemodynamic cerebral ischemia: the Carotid Occlusion Surgery Study randomized trial. JAMA 2011;306:1983-92.

6. Terada T, Yamaga H, Tsumoto T, et al. Use of an embolic protection system during endovascular recanalization of a totally occluded cervical internal carotid artery at the chronic stage. Case report. J Neurosurg 2005;102:558-64.

7. $\mathrm{Xu} Z$, Wang J, Luo B. Interventional recanalization as a treatment of carotid stump syndrome caused by right internal carotid artery occlusion: A case report. Medicine (Baltimore) 2019;98:e17152.

8. Cagnazzo F, Dargazanli C, Lefevre PH, et al. Chronic occlusion of the internal carotid artery: Endovascular revascularization technique of long occlusive lesions. J Neuroradiol 2020;47:318-22.

9. Bigliardi G, Dell'Acqua ML, Vallone S, et al. "Opening the Unopenable": Endovascular Treatment in a Patient with Three Months' Internal Carotid Artery Occlusion and Hemispheric Symptomatic Hypoperfusion. J Stroke Cerebrovasc Dis 2016;25:2016-8.

10. Rostambeigi N, Khatri R, Hassan AE, et al. Duplex ultrasound assisted endovascular revascularization of chronic internal carotid artery occlusion: technical note. J Vasc Interv Neurol 2013;6:42-6.

11. Iwata $\mathrm{T}$, Mori $\mathrm{T}$, Tajiri $\mathrm{H}$, et al. Long-term angiographic and clinical outcome following stenting by flow reversal technique for chronic occlusions older than 3 months of the cervical carotid or vertebral artery. Neurosurgery 2012;70:82-90; discussion 90.

12. Shojima M, Nemoto S, Morita A, et al. Protected endovascular revascularization of subacute and chronic total occlusion of the internal carotid artery. AJNR Am J Neuroradiol 2010;31:481-6.

13. Kim WH, Min PK, Kim DJ, et al. Successful carotid stenting for chronic total occlusion of the internal carotid artery. Korean Circ J 2010;40:288-91.

14. Hauck EF, Ogilvy CS, Siddiqui AH, et al. Direct endovascular recanalization of chronic carotid occlusion: should we do it? Case report. Neurosurgery 2010;67:E1152-9.

15. Bhatt A, Majid A, Kassab M, et al. Chronic total symptomatic carotid artery occlusion treated successfully with stenting and angioplasty. J Neuroimaging 2009;19:68-71.

16. Thomas AJ, Gupta R, Tayal AH, et al. Stenting and angioplasty of the symptomatic chronically occluded carotid artery. AJNR Am J Neuroradiol 2007;28:168-71.

17. Komiyama M, Yoshimura M, Honnda Y, et al. Percutaneous angioplasty of a chronic total occlusion of the intracranial internal carotid artery. Case report. Surg Neurol 2006;66:513-8.

18. Ishihara H, Sakai N, Kuroiwa T, et al. Percutaneous transluminal angioplasty and stenting for chronic total 
occlusion of intracranial carotid artery: a case report. Interv Neuroradiol 2006;12:263-8.

19. Terada T, Okada H, Nanto M, et al. Endovascular recanalization of the completely occluded internal carotid artery using a flow reversal system at the subacute to chronic stage. J Neurosurg 2010;112:563-71.

20. Namba K, Shojima M, Nemoto S. Wire-probing technique to revascularize subacute or chronic internal carotid artery occlusion. Interv Neuroradiol 2012;18:288-96.

21. Xia ZY, Yang H, Xu JX, et al. Effect of stenting on patients with chronic internal carotid artery occlusion. Int Angiol 2012;31:356-60.

22. Fan YL, Wan JQ, Zhou ZW, et al. Neurocognitive improvement after carotid artery stenting in patients with chronic internal carotid artery occlusion: a prospective, controlled, single-center study. Vasc Endovascular Surg 2014;48:305-10.

23. Hasan D, Zanaty M, Starke RM, et al. Feasibility, safety, and changes in systolic blood pressure associated with endovascular revascularization of symptomatic and chronically occluded cervical internal carotid artery using a newly suggested radiographic classification of chronically occluded cervical internal carotid artery: pilot study. J Neurosurg 2018:1-10. [Epub ahead of print]. doi: 10.3171/2018.1.JNS172858.

24. Chen YH, Leong WS, Lin MS, et al. Predictors for Successful Endovascular Intervention in Chronic Carotid Artery Total Occlusion. JACC Cardiovasc Interv 2016;9:1825-32.

25. Kao HL, Hung CS, Li HY, et al. Long-term Outcomes After Endovascular Recanalization in Patients with Chronic Carotid Artery Occlusion. Am J Cardiol 2018;122:1779-83.

26. Yeh CF, Chen YH, Lin MS, et al. Carotid-cavernous fistula after endovascular intervention for chronic carotid artery total occlusion. Catheter Cardiovasc Interv 2018;91:735-41.

27. Jiang WJ, Liu AF, Yu W, et al. Outcomes of Multimodality In situ Recanalization in Hybrid Operating Room (MIRHOR) for symptomatic chronic internal carotid artery occlusions. J Neurointerv Surg 2019;11:825-32.

28. Li J, Wang C, Zou S, Liu Y, et al. Hybrid Surgery for Nontaper or Nonstump Lesions in Symptomatic Subacute or Chronic Internal Carotid Occlusion: A Better Solution. World Neurosurg 2019;122:e1416-25.

29. Ricotta JJ, Aburahma A, Ascher E, et al. Updated Society for Vascular Surgery guidelines for management of extracranial carotid disease: executive summary. J Vasc Surg 2011;54:832-6.
30. Naylor AR, Ricco JB, de Borst GJ, et al. Editor's Choice - Management of Atherosclerotic Carotid and Vertebral Artery Disease: 2017 Clinical Practice Guidelines of the European Society for Vascular Surgery (ESVS). Eur J Vasc Endovasc Surg 2018;55:3-81.

31. Moher D, Shamseer L, Clarke M, et al. Preferred reporting items for systematic review and meta-analysis protocols (PRISMA-P) 2015 statement. Syst Rev 2015;4:1.

32. Huang CC, Chen YH, Lin MS, et al. Association of the recovery of objective abnormal cerebral perfusion with neurocognitive improvement after carotid revascularization. J Am Coll Cardiol 2013;61:2503-9.

33. Barnett HJ, Taylor DW, Eliasziw M, et al. Benefit of carotid endarterectomy in patients with symptomatic moderate or severe stenosis. North American Symptomatic Carotid Endarterectomy Trial Collaborators. N Engl J Med 1998;339:1415-25.

34. Sangiorgi G, Colombo A. Embolic protection devices. Heart 2003;89:990-2.

35. Johansson E, Fox AJ. Carotid Near-Occlusion: A Comprehensive Review, Part 1--Definition, Terminology, and Diagnosis. AJNR Am J Neuroradiol 2016;37:2-10.

36. Lee CW, Lin YH, Liu HM, et al. Predicting procedure successful rate and 1-year patency after endovascular recanalization for chronic carotid artery occlusion by CT angiography. Int J Cardiol 2016;221:772-6.

37. Parodi J, Bates MC, Ohki T, et al. The history of proximal carotid protection and flow reversal to prevent stent angioplasty embolization. Semin Vasc Surg 2018;31:9-14.

38. Huibers AE, Westerink J, de Vries EE, et al. Editor's Choice - Cerebral Hyperperfusion Syndrome After Carotid Artery Stenting: A Systematic Review and Metaanalysis. Eur J Vasc Endovasc Surg 2018;56:322-33.

39. Lin MS, Chiu MJ, Wu YW, et al. Neurocognitive improvement after carotid artery stenting in patients with chronic internal carotid artery occlusion and cerebral ischemia. Stroke 2011;42:2850-4.

40. Pires Coelho A, Lobo M, Gouveia R, et al. Overview of evidence on emergency carotid stenting in patients with acute ischemic stroke due to tandem occlusions: a systematic review and meta-analysis. J Cardiovasc Surg (Torino) 2019;60:693-702.

Cite this article as: Myrcha P, Gloviczki P. A systematic review of endovascular treatment for chronic total occlusion of the internal carotid artery. Ann Transl Med 2021;9(14):1203. doi: 10.21037/atm-20-6980 